\title{
Correlation between Suppression of Tumorigenicity-2 with Left Ventricular Geometry, Left Ventricular Ejection Fraction and Quality of Life in Systolic Heart Failure Patients
}

\author{
Johan Gunadi*, Starry Homenta Rampengan, Janry Antonius Pangemanan, Agnes Lucia Panda, \\ Nancy Lampus, Hasjim Hasbullah \\ Department of Cardiovascular, Faculty of Medicine, Universitas Sam Ratulangi, Jl. Raya Tanawangko No 56, Manado 955234, Indonesia \\ *Corresponding author. E-mail: joguntos@gmail.com
}

Received date: Aug 1, 2019; Revised date: May 29, 2020; Accepted date: July 7, 2020

\section{Abstract}

$\mathrm{B}$ ACKGROUND: Heart failure (HF) is a clinical syndrome caused by structural or functional cardiac disorders and is the final stage of every heart disease, marked by decreased functional capacity and patients' quality of life (QoL). Suppression of tumorigenicity-2 (ST2) is a biomarker depicting heart fibrosis and remodeling that altered left ventricular geometry, which in turn decreases left ventricular contractility, decreases functional capacity, and ultimately affects the QoL of the HF patient.

METHODS: An observational study was conducted with a cross-sectional approach involving 60 patients with systolic heart failure. Left ventricular geometry, left ventricular ejection fraction (LVEF), ST2 level, and other biomarkers were examined, continued by QoL assessment.
RESULTS: The ST2 level $(33.25 \pm 23.55 \mathrm{ng} / \mathrm{mL})$ was negatively correlated with LVEF $(\mathrm{r}=-0.257 ; p=0.024)$ and was positively correlated with QoL $(\mathrm{r}=0.255 ; p=0.05)$. The LVEF was negatively correlated with QoL $(\mathrm{r}=-0.224$; $p=0.031$ ). However, no significant correlation was found between left ventricular geometry with ST2 level or patients' QoL.

CONCLUSION: Elevated ST2 levels are correlated with decreased LVEF and worse QoL in systolic heart failure subjects. Therefore, ST2 together with LVEF can be used as prognostic tools for patients with HF.

KEYWORDS: heart failure, ST2, left ventricular geometry, left ventricular ejection fraction, quality of life

Indones Biomed J. 2020; 12(3): 233-8

\section{Introduction}

Heart Failure (HF) has become a worldwide problem. More than 915,000 new cases were reported in USA with five years mortality rate of $52.6 \%(24.4 \%$ at age 60 and $54.4 \%$ at age 80$)$. $(1,2)$ The incidences of HF in developing countries vary from $1.5-9.9 \%$. Data from Indonesian National Basic Health Research showed a prevalence of $0.5 \%$ for $\mathrm{HF}$ in 65 74 years old population, and this number increased to $1.1 \%$ in population with age $\geq 75$ years. $(1,3,4)$ HF can be simply defined as a failure of heart muscle to pump blood in the rate it should be, to meet the needs of tissue metabolism.(2) HF known as the final stage of almost all kind of cardiovascular diseases (CVD).

Cardiac remodeling in HF, refers to changes in the heart's size, shape, structure, and function. Current modality to assess the remodeling is echocardiography. The echocardiography examination primarily focusing on assessing the left ventricular geometry, i.e., the left ventricular hypertrophy $(\mathrm{LVH})$ with or without left atrial enlargement, and the left ventricular diastolic function.(5) Severe heart remodeling will lead to a decrease in muscle contractility in HF patients, impact in decreased ability of daily activities, and of course the patient's Quality of Life (QoL), which then will increase morbidity and 
rehospitalization.(6) Thus, knowing the rate of cardiac muscle damage at an earlier stage will help to manage better strategies for the patients.

Some biomarkers including B-type natriuretic peptide (BNP), N-terminal-proBNP (NT-proBNP), and High Sensitivity Troponin were recently considered as the tools to assess the damage of the heart muscle and prognosing the HF. However, the prognostic utility of natriuretic peptides is still limited and its role for treatment guidance has not yet been clearly established.(7) Suppression of tumorigenicity 2 (ST2) is a member of the interleukin 1 receptor family, also known as interleukin 1 receptor-like 1 (IL1RL-1).(8) The expression of ST2 upon cardiomyocytes stress, drew attention to encourage ST2 as a biomarker for fibrosis and cardiac remodeling. ST2 can predict the incidence of HF, rehospitalization, death, and cardiovascular adverse events. Monitoring ST2 levels can be useful to assess the patient's respond to treatments and can dynamically illustrate the clinical status of a patient's development.(9) Therefore, this study was aimed to observe the use of ST2 levels for prognosting patients with HF.

\section{Methods}

\section{Subjects}

This study has been approved by the Ethic Committee for Research of Prof. Dr. Kandou Hospital (No. PP 04.03/ XIX.2/995-1/2017). All subjects provided written informed consent. A cross-sectional study was conducted involving 60 subjects with ejection fraction $(\mathrm{EF}) \leq 40 \%$ (based on ACC/ AHA Guideline on the Primary Prevention of Cardiovascular Disease), and were able to perform six minutes walking test in Clinic of Cardiovascular, Prof. Dr. Kandou Hospital, Manado, from October to December 2017. Subjects with uncompensated acute heart failure, autoimmune disease, and sepsis were excluded. Physical anamneses and echocardiography were performed to subjects after filling the QoL questionnaire, continued with blood drawing from median cubital vein for ST2 measurements.

\section{QoL Assessment}

The QoL was determined from total score of the Indonesian version of Minnesota Living with Heart Failure Questionnaire (MLHFQ) which consisted of 21 questions with 6-point scale (0-5) The questionnaire used to evaluate the effect of heart failure and treatment on patient's QoL. There were two domains in the questionnaire which were 8 physical domains questions and 5 emotional domains questions and the other miscellaneous 8 questions. The higher the MLHFQ score, the lower the QoL of patient.(10)

\section{Soluble ST2 (sST2) Measurement}

The sST2 level was measured from frozen aliquot serum $\left(-80^{\circ} \mathrm{C}\right)$. The aliquot was thawed, left in room temperature, and used for sST2 quantification by immunochromatographic methods using ASPECT-PLUS ST2 rapid test (Critical Diagnostics, San Diego, CA, USA). The ASPECTPLUS ST2 test cassette was warmed under room temperature for 15 minutes, before 30-40 mL serum sample was dropped into the well. Two drops of test buffer was added. The ASPECT-PLUS ST2 test cassette was then inserted into the ASPECT reader (Critical Diagnostics, San Diego, CA, USA). The sST2 levels $(\mathrm{ng} / \mathrm{mL})$ were displayed after \pm 20 minutes and recorded.(11)

\section{Geometry and Left Ventricular Ejection Fractions (LVEF) Assessment}

Geometric and LVEF assessments were performed by echocardiography using Epiq5 (Phillips, Amsterdam, Netherland) based on The original American Society of Echocardiography (ASE). The assessments were performed on parasternal long axis, parasternal short axis, apical 4-chamber, and apical 2-chamber view. The linear measurements of LV internal dimension (LVDd), interventricular septal (IVS), and posterior wall (PW) were made from the parasternal long-axis acoustic window at the level of the LV minor axis, approximately at the mitral valve leaflet tips. The EF was measured on echocardiography using Simpson's biplane method.

\section{Statistical Analysis}

Statistical analysis was performed using SPSS v21.0 (IBM Corporation, Armonk, New York, USA). Demographics and clinical and laboratory variables were generally described as means with SD using univariate descriptive analysis. Mann-Whitney test was performed to assess the variables' differences. The correlation between variables were evaluated by bivariate analysis with Spearman and Pearson correlation test. The value of correlation coefficient grouped according to De Vaus, $p$-values $<0.05$ considered significant.

\section{Results}

\section{Clinical and Laboratory Characteristics of Subjects}

From October to December in 2017, 60 patients have been participated in this study. As much as $78.3 \%$ subjects in this 
Table 1. Basic characteristics of the study subjects.

\begin{tabular}{lccc}
\hline \multicolumn{1}{c}{ Variable } & Mean \pm SD & Minimum & Maximum \\
\hline ST2 (ng/mL) & $33.25 \pm 23.55$ & 12.50 & 125.00 \\
Age (years old) & $57.45 \pm 11.38$ & 30.00 & 85.00 \\
BH $(\mathrm{cm})$ & $161.38 \pm 8.09$ & 142.00 & 178.00 \\
BW $(\mathrm{kg})$ & $66.88 \pm 14.15$ & 35.00 & 98.00 \\
BMI $\left(\mathrm{kg} / \mathrm{m}^{2}\right)$ & $25.57 \pm 4.50$ & 16.20 & 36.58 \\
LVMI $\left(\mathrm{g} / \mathrm{m}^{2}\right)$ & $187.45 \pm 60.23$ & 84.00 & 334.00 \\
RWT & $0.32 \pm 0.07$ & 0.20 & 0.49 \\
LVEDD $(\mathrm{cm})$ & $6.53 \pm 0.95$ & 5.11 & 8.90 \\
IVSd $(\mathrm{cm})$ & $1.09 \pm 0.26$ & 0.69 & 1.84 \\
PWd (cm) & $1.02 \pm 0.16$ & 0.76 & 1.36 \\
EF (\%) & $31.50 \pm 7.67$ & 13.00 & 40.00 \\
MLHFQ & $36.50 \pm 7.79$ & 22.00 & 58.00 \\
\hline
\end{tabular}

ST: Suppression of tumorigenicity 2; BH: Body height; BW: Body weight; BMI: Body mass index; LVMI: Left ventricular mass index; RWT: Relative wall thickness; LVEDD: Left ventricular end diastolic diameter; IVSd: Interventricular septum thickness; PWd: Posterior wall thickness; EF: Ejection fraction; MLHFQ: Minnesota Living with Heart Failure Questionnaire.

study were male. The patients' basic characteristics could be found in Table 1. The mean value for age was $57.45 \pm 11.38$ years old. Subjects' EF was 31.5 $\pm 7.67 \%$, with minimum EF value of $13 \%$ and the maximum of $40 \%$. Fourty-two (70\%) patients have normal ST2 levels $(<35 \mathrm{ng} / \mathrm{mL})$ while 18 $(30 \%)$ patients have elevated ST2 levels, gave out a mean value of $33.25 \pm 23.55 \mathrm{ng} / \mathrm{mL}$.

The left ventricular geometric pattern measurement (Table 2) showed 7 patients (11.7\%) with normal geometry, 1 patient $(1.7 \%)$ with concentric remodeling, 48 patients $(80 \%)$ with eccentric hypertrophy, and 4 patients $(6.7 \%)$ with concentric hypertrophy. While the assessment of MLHFQ QoL showed mean score of $36.5 \pm 7.79$ with lowest score was 22 and highest score was 58.

However, in this study, there was no characteristic differences between the patients with normal or elevated ST2 level, as presented in Table 3.

\section{The Correlation between ST2 Levels with Left Ventricular Geometry and LVEF}

No significant correlation was found between ST2 level and left ventricular geometry $(\mathrm{r}=0.082, p=0.266)$, and also no significant correlation between ST2 levels and all left ventricular geometry parameter, including LVEDD ( $p=0.976)$, RWT ( $p=0.939)$, PWD ( $p=0.861)$, and at LVMI $(p=0.787)$. However, there was a significant negative but weak correlation between ST2 level and LVEF using Spearman correlation test $(\mathrm{r}=-0.257, p=0.024)$ (Figure 1A, Table 4).
Correlation between ST2 Levels, Left Ventricular Geometry, and LVEF with QoL

As illustrated in Table 5 and Figure 1B, ST2 levels was found to be positively correlated with $\mathrm{QoL}(\mathrm{r}=0.255$, $p=0.05$ ), while Left Ventricular Geometry, and LVEF showed a significant negative correlation with QoL.

\section{Discussion}

Many tools were used to assess systolic heart failure, including ST2 level, left ventricular geometry, and LVEF in

Table 2. Subjects description based on geometry of left ventricle and ST2 levels.

\begin{tabular}{lcc}
\hline \multicolumn{1}{c}{ Variables } & n & Percentage (\%) \\
\hline Gender & & \\
Men & 47 & 78.3 \\
Women & 13 & 21.7 \\
\hline Geometry of Left Ventricle & & \\
Normal & 7 & 11.7 \\
Remodeling Concentric & 1 & 1.7 \\
Eccentric hypertrophy & 48 & 80 \\
Concentric hypertrophy & 4 & 6.7 \\
\hline ST2 & & \\
$<35 \mathrm{ng} / \mathrm{mL}$ & 40 & 66.7 \\
$\geq 35 \mathrm{ng} / \mathrm{mL}$ & 20 & 33.3 \\
\hline
\end{tabular}


Table 3. Subjects characteristic based on ST2 levels.

\begin{tabular}{|c|c|c|c|c|}
\hline Variables & $\begin{array}{c}\text { Total } \\
(n=60)\end{array}$ & $\begin{array}{c}\mathrm{ST} 2<35 \mathrm{ng} / \mathrm{mL} \\
(\mathrm{n}=40)\end{array}$ & $\begin{array}{c}\mathrm{ST} 2 \geq 35 \mathrm{ng} / \mathrm{mL} \\
(\mathrm{n}=20)\end{array}$ & $p$-value \\
\hline Age (years old) & 57.45 & 58.75 & 54.85 & 0.146 \\
\hline $\mathrm{BH}(\mathrm{cm})$ & 161.38 & 160.53 & 163.10 & 0.386 \\
\hline BW (kg) & 66.80 & 67.90 & 64.85 & 0.242 \\
\hline BMI $\left(\mathrm{kg} / \mathrm{m}^{2}\right)$ & 25.56 & 26.18 & 24.33 & 0.9 \\
\hline $\operatorname{LVMI}\left(\mathrm{g} / \mathrm{m}^{2}\right)$ & 187.45 & 189.62 & 183.10 & 0.838 \\
\hline RWT & 0.32 & 0.32 & 0.32 & 0.937 \\
\hline $\operatorname{LVDD}(\mathrm{cm})$ & 6.53 & 6.54 & 6.53 & 0.987 \\
\hline PWd (cm) & 1.02 & 1.02 & 1.01 & 0.938 \\
\hline $\mathrm{EF}(\%)$ & 31.50 & 33.31 & 27.89 & 0.12 \\
\hline MLFHQ & 36.50 & 35.22 & 39.05 & 0.062 \\
\hline $\mathrm{ST} 2(\mathrm{ng} / \mathrm{mL})$ & 33.25 & 20.47 & 58.80 & $<0.001$ \\
\hline ACE-I/ARB & $100 \%$ & $100 \%$ & $100 \%$ & 1 \\
\hline Beta Blocker & $100 \%$ & $100 \%$ & $100 \%$ & 1 \\
\hline
\end{tabular}

ST: Suppression of tumorigenicity-2; BH: Body height; BW: Body weight; BMI: Body mass index; LVMI: Left ventricular mass index; RWT: Relative wall thickness; LVEDD: Left ventricular end diastolic diameter; IVSd: Interventricular septum thickness; PWd: Posterior wall thickness; EF: Ejection fraction; MLHFQ: Minnesota Living with Heart Failure Questionnaire; ACE-I: Angiotensin converting enzyme inhibitor; ARB: Angiotensin II receptor blocker. *Tested with Mann-Whitney.

order to determine patients' prognostic so better treatment strategies could me made. $(6,12-14)$ In this study, 40 patients $(66.7 \%)$ had normal ST2 levels $(<35 \mathrm{ng} / \mathrm{mL})$ and 20 patients (33.3\%) had elevated ST2 levels. EF and QoL in patients with normal ST2 levels was found to be different compared to those with higher ST2 levels, showed that patients who have higher ST2 levels suffer with lower EF and worse QoL, although it was not statistically significant. A study in 2013 involving 1670 male and 661 female patients reported an association between ST2 levels and functional capacity in HF patients from HF-action trial. They found that patients who have ST2 levels $\geq 35 \mathrm{ng} / \mathrm{mL}$ had a lower ejection fraction although are not statistically significant.(6)

There was no significant relationship between ST2 level with left ventricular geometry $(p=0.266)$ in this study. However, a significant negative relationship was found between ST2 level and LVEF, suggesting that higher ST2 level correlated with lower EF. Therefore, ST2 level can be
A

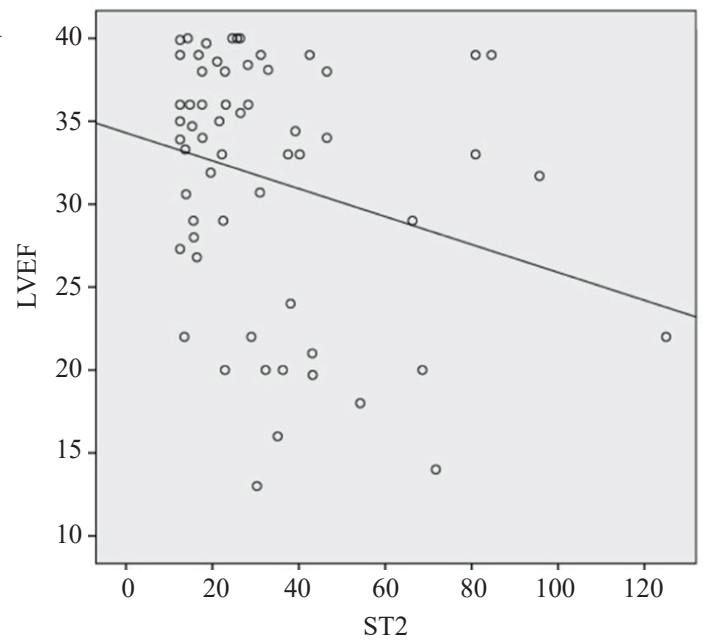

B

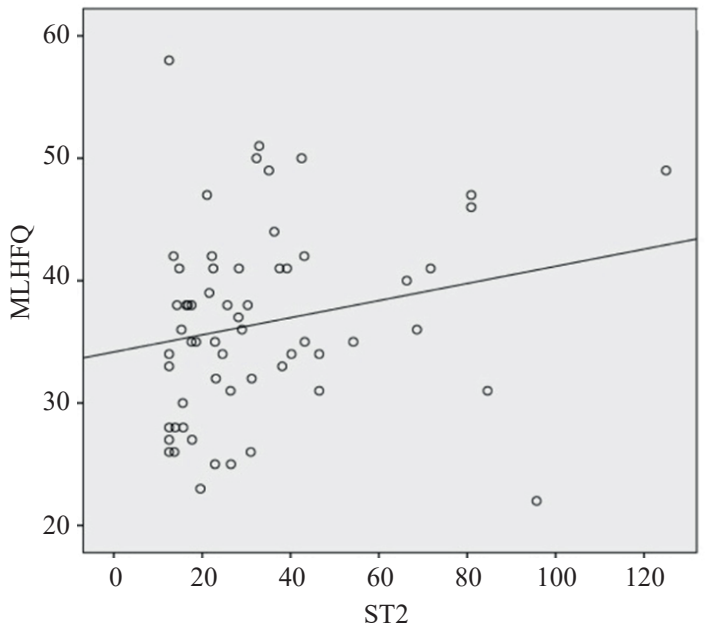

Figure 1. Correlation graphs of the related parameters. A: Correlation between ST2 levels and LVEF; B: Correlation between ST2 level and MLHFQ QoL. 
Table 4. Correlation between ST2 levels with left ventricle geometry and ejection fraction.

\begin{tabular}{lcc}
\hline \multicolumn{1}{c}{ Variable } & r & $\boldsymbol{p}$-value \\
\hline Left Ventricle Geometry & 0.082 & 0.266 \\
LVMI & 0.036 & 0.787 \\
RWT & -0.010 & 0.939 \\
LVEDD & 0.004 & 0.976 \\
PWd & -0.230 & 0.861 \\
Ejection Fraction & -0.257 & 0.024 \\
\hline
\end{tabular}

LVMI: Left ventricular mass index; RWT: Relative wall thickness; LVEDD: Left ventricular end diastolic diameter; PWd: Posterior wall thickness. *Tested with Spearman.

used together with the LVEF as prognostic tools, where high ST2 level with lower the LVEF defined a higher mortality rate.(15) Study performed on hypertension, hypertensive heart disease, and hypertensive HF patients showed a negative relationship between EF and ST2 level ( $\mathrm{r}=-0.6$, $p<0.05)$.(14) While another study on HF subjects with normal EF found no correlation between ST2 level and EF. $(14,16)$

Patients' therapies may affect the ST2 level correlation with the left ventricular geometry. Sub-analysis of proBNP Outpatient Tailored Chronic Heart Failure Therapy (PROTECT) study showed a significant decrease of ST2 levels among patients who received beta-blocker therapy. (17) This therapy may alter the left ventricular geometry as shown in the Beta-Blocker Evaluation of Survival Trial (BEST) sub-analyses, where an improvement in the left ventricular mass index was observed after beta blocker administration.(18) Similarly, the Valsartan Heart Failure

Tabel 5. Correlation between ST2 level, left ventricle geometry, and LVEF with MLHFQ QoL.

\begin{tabular}{lcc}
\hline \multicolumn{1}{c}{ Variable } & r & p-value \\
\hline ST2 & 0.255 & $0.050^{*}$ \\
LVMI & -0.037 & $0.781 * *$ \\
RWT & -0.168 & $0.199 * *$ \\
LVEDD & -0.210 & $0.874 * *$ \\
PWD & -0.218 & $0.094^{* *}$ \\
EF & -0.242 & $0.031 * *$ \\
\hline
\end{tabular}

ST2: Suppression of tumorigenicity 2, LVEF: Left ventricle ejection fraction; LVMI: Left ventricular mass index; RWT: Relative wall thickness; LVEDD: Left ventricular end diastolic diameter; PWd: Posterior wall thickness, EF: Ejection Fraction. *Tested with Spearman. **Tested with Pearson Test.
Trial study also showed a lower ST2 levels in subjects who received Angiotensin Converting Enzyme Inhibitor (ACE-I) or Angiotensin II Receptor Blocker (ARB).(17) Thus, a decrease of ST2 levels was observed on periodic examination in patients treated with a combination of ACE-I/ARB, beta blockers, and mineralocorticoid receptor antagonists (MRA).(19)

ST2 level is currently one of the most recognized markers for HF patient's prognostic assessment. Elevated ST2 level has shown to increase mortality and morbidity, also affect the QoL of patients with HF. Our study showed a significant correlation between elevated ST2 level and decreased QoL of patients with HF. This finding was consistent with one similar study although they performed a different questioner (Kansas City Cardiomyopathy Questionnaire).(6)

More than ST2 level, several echocardiographic parameters such as left ventricular geometry could be used as prognostic factors in patients with $\mathrm{HF}$, and also become one of the therapeutic targets for improving patients' QoL. There was no correlation between left ventricular geometry and its parameters with the patients' QoL in this study. However, there was a significant negative correlation between LVEF with the patients' QoL, where patients with lower EF have worse QoL. Left ventricular geometry affects patient's functional capacity which in turn will affect the QoL. This is consistent with a study conducted in 2013 which reported there was no correlation between left systolic functional parameters and functional capacity, but found the role of diastolic parameters in the functional capacity and systolic heart failure patients' QoL.(20) The limitation of this study was no observation made on HF medications effect on ST2 levels.

\section{Conclusion}

Elevated ST2 levels are correlated with decreased LVEF and worse QoL in systolic heart failure subjects. In addition to the ST2 level, the LVEF also showed a significant correlation with patients QoL. Therefore, ST2 together with LVEF can be used as prognostic tools for patients with HF.

\section{References}

1. Mozaffarian D, Benjamin EJ, Go AS, Arnett DK, Blaha MJ, Cushman M, et al. Heart disease and stroke statistics - 2016 update: a report from the American Heart Association. Circulation. 2016; 133: e38360 . 
2. Roger VL, Weston SA, Redfield MM, Hellermann-Homan JP, Killian $\mathrm{J}$, Yawn BP, et al. Trends in heart failure incidence and survival in a community-based population. JAMA. 2004; 292: 344-50.

3. Kemenkes RI. Riset Kesehatan Dasar 2013. Jakarta: Badan Penelitian dan Pengembangan Kesehatan RI; 2013.

4. Kemenkes RI. Situasi Kesehatan Jantung. Jakarta: Pusat Data dan Informasi Kementerian Kesehatan Republik Indonesia; 2014.

5. Daniels LB, Bayes-Genis A. Using ST2 in cardiovascular patients: a review. Future Cardiol. 2014; 10: 525-39.

6. Felker GM, Fiuzat M, Thompson V, Shaw LK, Neely ML, Adams $\mathrm{KF}$, et al. Soluble ST2 in ambulatory patients with heart failure: Association with functional capacity and long-term outcomes. Circ Heart Fail. 2013; 6: 1172-9.

7. Lilly LS. Pathophysiology of heart disease: a collaborative project of medical students and faculty. 6th edition. Philadelphia: Wolters Kluwer; 2016.

8. Villacorta H, Maisel AS. Soluble ST2 testing: a promising biomarker in the management of heart failure. Arq Bras Cardiol. 2016; 106: $145-52$.

9. Rampengan SH, Prihartono J, Siagian M, Immanuel S. The effect of enhanced external counterpulsation therapy and improvement of functional capacity in chronic heart failure patients: a randomized clinical trial. Acta Medica Indones. 2015; 47: 275-82.

10. Kusuma DY, Shatri H, Alwi I, Abdullah M. Validity and reliability studies of the Indonesian version of the Minnesota Living with Heart Failure Questionnaire (MLHFQ): uality of Life Questionnaire for Patients with Chronic Heart Failure. Acta Medica Indones. 2019; 51: 26-33.

11. Dieplinger B, Egger M, Gegenhuber A, Haltmayer M, Mueller T. Analytical and clinical evaluation of a rapid quantitative lateral flow immunoassay for measurement of soluble ST2 in human plasma. Clin Chim Acta Int J Clin Chem. 2015; 451: 310-5.

12. Mancia G, Fagard R, Narkiewicz K, Redon J, Zanchetti A, Böhm $\mathrm{M}$, et al. $2013 \mathrm{ESH} / \mathrm{ESC}$ guidelines for the management of arterial hypertensionThe Task Force for the management of arterial hypertension of the European Society of Hypertension (ESH) and of the European Society of Cardiology (ESC). Eur Heart J. 2013; 34: 2159-219.

13. Santos J, Brofman P. Six-minute walk test and quality-of-life in heart failure A correlative study with a Brazilian sample. Rev Insuf Card. 2008; III: 72-5.

14. Lavie CJ, Patel DA, Milani RV, Ventura HO, Shah S, Gilliland Y. Impact of echocardiographic left ventricular geometry on clinical prognosis. Prog Cardiovasc Dis. 2014; 57: 3-9.

15. Ojji DB, Opie LH, Lecour S, Lacerda L, Adeyemi OM, Sliwa K. The effect of left ventricular remodelling on soluble ST2 in a cohort of hypertensive subjects. J Hum Hypertens. 2014; 28: $432-7$.

16. Yancy CW, Jessup M, Bozkurt B, Butler J, Casey DE, Colvin MM, et al. 2017 ACC/AHA/HFSA focused update of the 2013 ACCF/ AHA guideline for the Management of Heart Failure: A Report of the American College of Cardiology/American Heart Association Task Force on Clinical Practice Guidelines and the Heart Failure Society of America. Circulation. 2017; 136: e137-61.

17. Gaggin HK, Motiwala S, Bhardwaj A, Parks KA, Januzzi JL. Soluble concentrations of the interleukin receptor family member ST2 and $\beta$-blocker therapy in chronic heart failure. Circ Heart Fail. 2013; 6: 1206-13.

18. AbouEzzeddine OF, McKie PM, Dunlay SM, Stevens SR, Felker $\mathrm{GM}$, Borlaug BA, et al. Suppression of tumorigenicity 2 in heart failure with preserved ejection fraction. J Am Heart Assoc. 2017 18;6: e004382. doi: 10.1161/JAHA.116.004382.

19. Bahuleyan CG, Alummoottil GK, Abdullakutty J, Lordson AJ, Babu S, Krishnakumar VV, et al. Prognostic value of soluble ST2 biomarker in heart failure patients with reduced ejection fraction A multicenter study. Indian Heart J. 2018; 70: S79-84.

20. Bussoni MF, Guirado GN, Roscani MG, Polegato BF, Matsubara LS, Bazan SGZ, et al. Diastolic function is associated with quality of life and exercise capacity in stable heart failure patients with reduced ejection fraction. Braz J Med Biol Res. 2013; 46: 803-8. 